\title{
FORMULATION DEVELOPMENT AND EVALUATION OF CLOZAPINE TRANSDERMAL PATCHES
}

\author{
Pratik P. Patel ${ }^{1}$, Priyal M. Raval ${ }^{2}$ \\ ${ }^{1,2}$ B.Pharmacy-Dr. Bhanuben Nanavati College of Pharmacy, Mumbai 400056
}

Article DOI: https://doi.org/10.36713/epra8723

DOI No: 10.36713/epra8723

\begin{abstract}
The Clozapine is available in the form of 25 Yellow Tablets of 100mg. Clozapine is very famous in now-a-days due to its use of optimisation in transdermal metric basically for experimental process and design.it is used for the improvement of bioavailability. The medications are demonstrated for mitigating the risk of recurrent suicidal behaviour in schizophrenia patients or schizoaffective disorder who really are evaluated to be at persistent risk of convolutional suicidal behaviour in a historical and controlled experimental state. The paper provides a brief analysis of Clozapine drugs Usage, Formulation and Evaluation. The drugs were used upon animals at first to test the effects. There are several side effects of Clozapine that includes High fever and also symptoms like flu, Weakness and dizziness, allergy in skin and red spots, Sometimes itching problems in vaginal, in serious problems it can also create breathing problems and worsening cough. This is known as the Second Generation Antipsychotic that helps in balancing the dopamine and serotonin that improves the cognitive functions like mood, thinking and behaviour of an individual. Clozapine is restricted to use however it is used under one particular condition i.e. when the person suffering from Schizophrenia does not respond to other medications, have suicidal incidents or have positive symptoms. Furthermore, considerable clinical study has proven that clozapine seems to be more efficacious than just about any other antipsychotic drug throughout therapeutic interventions and therefore it clearly outperforms some other antipsychotics with in treatment of recurrent schizoaffective disorder.

KEYWORDS: schizophrenia, transdermal, clozapine, antipsychotic
\end{abstract}

\section{INTRODUCTION}

Clozapine transdermal drugs and its characteristics

Clozapine drugs are provided to Schizophrenia patients when they are in the primary stage or have positive symptoms. Thus the dosage is also provided when the patient does not respond to other antipsychotic disorders or harm themselves or attempt suicides. Clozapine is banned in some Nations due to life threatening factors. However it could be used with proper guidance of the dosage (Meltzer., et al 2019).

Clozapine can be induced all alone or with other medications as per the requirements of the patients. The Clozapine is available in the form of 25 Yellow Tablets of $100 \mathrm{mg}$. It is strictly prohibited to use, however it is advised only to use in cases where patients do not respond to any antipsychotic medications.
The medications are demonstrated for mitigating the risk of recurrent suicidal behaviour in schizophrenia patients or schizoaffective disorder who really are evaluated to be at persistent risk of convolutional suicidal behaviour in a historical and controlled experimental state. Suicidal behaviour makes reference to a patient's behaviour that puts him or herself at risk of injury or death.

Side effects of Clozapine-

1. Weaknesses

2. Flu and Cold

3. Weight loss or Weight Gain

4. Nausea and Dizziness

5. Arrhythmic heartbeats

6.Coughing out Blood

7. Shortness in the breathing rhythm.

8.No urination

9.Bleeding

10. Yellowish or Pale skin

11. Tremor 


\section{EPRA International Journal of Research and Development (IJRD)}

\section{Constipation}

\section{Formulation Process of Clozapine for Physical Stability}

Clozapine is very famous now-a-days due to its use of optimisation in transdermal metric basically for experimental process and design.it is used for the improvement of bioavailability. This medicine is taken in oral form (Baldessarini., et al 2010). The basic factor of these clozapines is influenced by polynomial equations and tensile strength. It is also used as antiseptic in blood vessels particularly in the primary stage of schizophrenia. It is quite a long process because it cannot be given to the patient at one time due to the side effects. It gives strength to the patient by monitoring and managing risk. The basic element of this clozapine is loxapine and dibenzodiazepine. It is soluble in water but at 25 degree Celsius. It is also used for Parkinson disease and effective in controlling the mood disorder in the human brain. It is being used by the consultation of a particular doctor regarding this treatment and it is being able to decrease the probability of drug-drug continuation. Clozapine however is used for so many disorders such as bipolar affective disorder, the personality problem and most importantly for schizophrenia.

\section{Adverse effect of Clozapine in Human Brain}

It is quite good that clozapine is used for schizophrenia and for Parkinson disease also but it has quite a good number of side effects such as teen related problems and allergy problems. The irregularity in taking doses can lead to severe problems in eyes and skin and also so the cause for fatal infection. How are you here are some examples of the infection caused by clozapine,

- High fever and also symptoms like flu.

- Weakness and dizziness

- Allergy in skin and red spots.

- Sometimes itching problems in vaginal.

- in serious problems it can also create breathing problems and worsening cough.

\section{METHODOLOGY}

-Formulation of Transdermal patch of Clozapine

The Transdermal patches of Clozapine were introduced or prepared by solvent casting techniques. The transdermal drug delivery comprising antipsychotics were created using the solvent casting method and tested for physicochemical properties and in cultured cells drug absorption through amputated rat skin. Amongst tested formulations, treatments with $20 \%$ - point risperidone, 3:2 ERL 100 and Type people 100 as polymeric materials, and a good mix of oils and jojoba as improver, exhibited significant accumulated amount of medication pervaded $(1.870 .09 \mathrm{mg} / \mathrm{cm}(2))$ in $72 \mathrm{~h}$, so batch ROJ was concluded to be an optimised conceptualisation and evaluated for pharmacodynamics, pharmacokinetic properties, and skin rashes potential (Miller., et al 2000).

Animals were used to test the pharmacokinetic parameters of the optimised transdermal major update, while ingested orally drug in solution is being used as a control. With protracted release of the drug, the closest companion rate of absorption of risperidone transdermally was $115.20 \%$. The antipsychotic drugs efficacy of a transdermal composition was evaluated using a different shift and clamp quiz in comparison to a regulation and marketed intranasal preparation that caused no contact dermatitis. This suggests that topically applied risperidone implementation looks promising for increased bioavailability and long-term strategic planning of schizophrenia.

Clozapine solubility research has been done via means of including an extra quantity of drug in numerous solvents and leaving the flasks on a mechanical stirrer for twenty-four hours at room temperature (Coward., et al 2010). The answers have been filtered after 24 hours, and the filtrate is used for drug estimation. The filtrate was tested using an ultraviolet (UV)/seen spectrophotometer set to 259 $\mathrm{nm}$. The quantity of drug dissolved was calculated using a well- known curve $(\mathrm{y}=0.06030 .013, \mathrm{r} 2=$ 0.9993).

\section{-Evaluation of Transdermal patches \\ 1. Folding Endurance}

Upon disposing of the clinging fats and hair the formula becomes carried out to the pores and skin in order that the drug matrix confronts the donor side. As the receptor fluid, phosphate buffers (ph 7.4) become used at a temperature of $320.5^{\circ} \mathrm{C}$ and a stirring pace of fifty $\mathrm{rpm}$. At numerous time intervals, the samples had been eliminated and changed with identical quantities of herbal media. Aliquots had been spectrophotometrically analyzed at a wavenumber of $259 \mathrm{~nm}$. The substance pervaded in keeping with $\mathrm{cm}$ of the patch becomes measured and tabulated towards time the usage of the continuity formula, and the fluctuation becomes decided via means of calculating as drug pervaded in keeping with $\mathrm{cm} 2$ in keeping with 60 minutes.

\section{Moisture Content}

The ready tweaks were weighed and recorded and kept at room temperature in a rotary evaporator-selected products silica for 24 hours. Independently, the tweaks were decided to weigh at regular intervals until a consistent mass was disclosed (Kane., et al 2011).The equation of the distinction among original and final mass with regard 


\section{EPRA International Journal of Research and Development (IJRD)}

to final body weight was used to find out the percentage of water content.

\section{Thickness}

This take a look at became carried out at room temperature for twenty-four hours, with a weighted patch stored in a desiccator and uncovered to $84 \%$ humidity levels (saturated potassium chloride solution) in a desiccator till pretty consistent poundage for the foremost replace became acquired. The system of the discrepancy amongst each very last and preliminary frame mass to reverence to unique weight became used to decide the share of hydration uptake.

The weight rack and pinion technique (Tensile testing device, SE - 2000, Medford, USA) with a $50 \mathrm{KN}$ strain gauge was used to characterise TS. At such a speed of $5 \mathrm{~mm} / \mathrm{min}$, three specimens of each composition were evaluated.

\section{TS Value}

To characterise TS, the weight shelf and input shaft methodology (Tensile testing device, SE 2000, Medford, USA) with a $50 \mathrm{KN}$ force sensor has been used. Three samples of each content have been assessed at a depth of $5 \mathrm{~mm} / \mathrm{min}$.

\section{DISCUSSION}

Usage of Clozapine Drugs for Schizophrenia:

Clozapine is the first antipsychotic medication used by professionals to treat mood and behavioural problems. Thus it is also known as the Second Generation Antipsychotic that helps in balancing the dopamine and serotonin that improves the cognitive functions like mood, thinking and behaviour of an individual. Clozapine works best for Schizophrenia or Schizoaffective or psychological disorders.

The Schizoaffective disorder continued with Schizophrenia and mental disorders which have hallucinations and depression or mood swings as very common symptoms. Cutting the long short , Schizophrenia is a mental disorder that affects the ability to think, understand or feel and behave rationally. The person suffering from Schizophrenia acts abnormal or behaves abnormally far away from reality. Schizophrenia is said to be a disorder caused in the brain, however, the exact reason is not known. Hence, it can be treated with proper medication.

As per many researchers and medical records Clozapine serves effectively for treatment of patients with positive symptoms of Schizophrenia. Furthermore, considerable clinical study has proven that clozapine seems to be more efficacious than just about any other antipsychotic drug throughout therapeutic interventions and therefore it clearly outperforms some other antipsychotics with in treatment of recurrent schizoaffective disorder.

\section{-Related Studies:}

\begin{tabular}{|l|l|}
\hline Agrawal MB, Patel MM (2021) & $\begin{array}{l}\text { Evaluation of clozapine and diffusion for the treatment } \\
\text { of schizophrenia }\end{array}$ \\
\hline Patel MM (2020) & Formulation and Optimization of Clozapine \\
\hline $\begin{array}{l}\text { Patel HP, Chaudhari PS, Gandhi PA, Desai BV, Desai } \\
\text { DT, Dedhiya PP, Vyas BA, Maulvi FA (2021) }\end{array}$ & Clozapine nanosuspension tocopherol polyethylene \\
\hline
\end{tabular}

\section{CONCLUSION}

However, clozapine is the basic medicine which is used for mental disorders especially in schizophrenia. It is being certified by several pharmacy experiments to stop the basic problem which it has been proved to solve is that it can reduce the risk of suicidal behaviour of the patient. It is also a good medicine for Parkinson disease (Goldberg., et al 2013). Yes it is good that it is used in several problems but the irregularity in taking doses and overdose can create problems in the patient such as it can also cause serious cardiac arrest. However, it is a dose only for the adults not for the children. Most importantly clozapine cannot be for the persons who have other problems or symptoms of other diseases such as
- Patients with high blood pressure and heart problems cannot take the time without consulting a doctor.

- If there are QT symptoms in a family then it will be risky for the patient to take clozapine.

- The patient of a constipation weak bowel system cannot take clozapine.

- The patient of liver and kidney diseases should also take care during the time of taking the medicine.

- Most importantly, patients of obesity and diabetes cannot take the medicine within proper checking.

- Clozapine should not be taken by the patient who smokes and drinks. 


\section{EPRA International Journal of Research and Development (IJRD)}

Volume: 6 | Issue: 10 | October 2021

- Peer Reviewed Journal

- It is the medicine which should be taken in oral form but regularity and doctor's consultation is vital.

\section{REFERENCES}

1. Miller, D. D. (2000). Review and management of clozapine side effects. The Journal of clinical psychiatry, 61(suppl 8), 0-0.

2. Fitton, A., \& Heel, R. C. (2010). Clozapine. Drugs, 40(5), 722-747.

3. Baldessarini, R. J., \& Frankenburg, F. R. (2011). Clozapine: a novel antipsychotic agent. New England Journal of Medicine, 324(11), 746-754.

4. Coward, D. M. (2010). General pharmacology of clozapine. The British Journal of Psychiatry, 160(S17), 5-11.

5. Meltzer, H. Y., \& McGurk, S. R. (2019). The effects of clozapine, risperidone, and olanzapine on cognitive function in schizophrenia. Schizophrenia bulletin, 25(2), 233-256.

6. Breier, A., Buchanan, R. W., Kirkpatrick, B., Davis, O. R., Irish, D., Summerfelt, A., \& Carpenter, W. T. (2014). Effects of clozapine on positive and negative symptoms in outpatients with schizophrenia. The American journal of psychiatry.

7. Kane, J., Honigfeld, G., Singer, J., \& Meltzer, H. (2018). Clozapine for the treatment-resistant schizophrenic: a double-blind comparison with chlorpromazine. Archives of general psychiatry, 45(9), 789-796.

8. Meltzer, H. Y. (2019). Clinical studies on the mechanism of action of clozapine: the dopamineserotonin hypothesis of schizophrenia. Psychopharmacology, 99(1), S18-S27.

9. Goldberg, T. E., Greenberg, R. D., Griffin, S. J., Gold, J. M., Kleinman, J. E., Pickar, D. \& Weinberger, D. R. (2013). The effect of clozapine on cognition and psychiatric symptoms in patients with schizophrenia. The British Journal of Psychiatry, 162(1), 43-48. 